\title{
FERNANDO SÁNCHEZ DE CASTRO DESDE LA CRONÍSTICA: POLÍTICA MEDITERRÁNEA Y REBELIÓN DE UN HIJO BASTARDO DE JAIME I
}

\author{
FERNANDO SÁNCHEZ DE CASTRO LIFE BASED ON CHRONICLES: \\ MEDITERRANEAN POLITICS AND THE REBELLION OF JAIME I'S BASTARD SON
}

\section{JAIME ELIPE SORIANO}

Universidad de Zaragoza*

Resumen: A partir de las crónicas de época medieval y moderna, se elabora una biografía de Fernando Sánchez de Castro, hijo extramatrimonial de Jaime I y I barón de Castro. Se analiza la importancia del personaje desde los tres momentos clave de su vida: el viaje a Sicilia, la expedición a Tierra Santa y la rebelión contra el rey Jaime I y el infante Pedro. Se intenta esbozar la influencia que tuvieron en sus decisiones Manfredo de Sicilia y Carlos de Anjou.

Palabras clave: Fernando Sánchez de Castro, Jaime I de Aragón, Carlos de Anjou, Manfredo de Sicilia, Aragón.

\begin{abstract}
The biography of Fernando Sánchez de Castro (Jaime I's bastard son) is written based on Medieval and Modern chronicles. In it the importance of the historical figure relies on three key moments in his life, namely his journey to Sicily, his expedition to the Holy Lands, and his rebellion against King Jaime I and Prince Pedro. The biography constitutes an attempt to address the influence that Manfred of Sicily and Charles of Anjou had on Sánchez de Castro's decisions.

Keywords: Fernando Sánchez de Castro, Jaime I of Aragon, Charles of Anjou, Manfred of Sicily, Aragon.
\end{abstract}

\footnotetext{
* Mis agradecimientos a la doctoras María Narbona Cárceles y Asunción Blasco Martínez, los editores y evaluadores de la revista por sus ánimos, reflexiones y correcciones. También a aquellos que han soportado interminables debates sobre Federico II, bastardos y Sicilia.
} 
"Replicó Esaú a su padre: «¿Solo tienes una bendición, padre mío? Padre, bendíceme también a mí». Esaú rompió a llorar a gritos. Entonces su padre Isaac le respondió:

«Lejos de la tierra fértil tendrás tu morada,/ y lejos del rocío del cielo./

Vivirás de tu espada,/ y servirás a tu hermano./

Y cuando te rebeles,/ sacudirás el yugo de tu cuello»".

Génesis, XXVII, 38-40.

\section{INTRODUCCIÓN}

Fernando Sánchez de Castro (1241-1275) fue el mayor de los hijos bastardos de Jaime I de Aragón. La información disponible sobre su figura es muy reducida en la cronística medieval y moderna, debido principalmente a que fue famoso por acaudillar la rebelión de los nobles aragoneses y catalanes contra su padre. Por lo tanto, existen muy pocas noticias que puedan ilustrar algo de su vida.

La biografía que se puede elaborar a partir de los datos extraídos de las fuentes es escueta pero ayuda a tener una semblanza general de dicho personaje. La revuelta contra el rey Jaime I no fue un acontecimiento de causas endógenas. Estaba conectado con la política internacional del momento, fundamentalmente las ambiciones mediterráneas de Carlos de Anjou, hermano del rey Luis IX de Francia.

Básicamente, con los datos disponibles sobre su vida se pueden reseñar tres hitos principales: la gestión de la boda de su hermanastro el infante Pedro, la expedición a Ultramar y la revuelta contra su padre, Jaime I, que le acabó costando la vida.

Para cubrir dichos episodios, las crónicas manejadas en el presente artículo son aquellas que más información, a priori, podrían arrojar sobre el personaje en cuestión. En primer lugar y como obra de referencia, Libro de los hechos, mandado redactar por el mismo Jaime $\mathrm{I}^{1}$. Ofrece información de primera mano que, evidentemente, ha de ser valorada con cuidado ${ }^{2}$. La

1.- JAIme I, Libro de los hechos, (ed. Julia Butiñá), Madrid, Biblioteca Universal Gredos, 2003.

2.- Baste la introducción realizada por la editora en ibídem o Concepción VILLANueva MoRTE, "El reino de Aragón en la crónica de Jaime I", en Juan Francisco Jiménez, Jorge Maíz Chacón, Concepción Villanueva Morte, Inés Calderón Medina (eds.), IV Simposio internacional de jóvenes medievalistas, Murcia, 2009, pp. 239-272. 
Crónica de Bernat Desclot también es de interés, pero tiene el inconveniente de que pertenecía al círculo áulico de Pedro III, quien dio muerte a Fernando Sánchez ${ }^{3}$. El resto de obras medievales importantes no proporcionan datos que no cubran ya las anteriores ${ }^{4}$. Respecto a los historiadores de época moderna, el de mayor utilidad es Zurita por lo prolijo en detalles y calidad historiográfica. Jerónimo de Blancas, por su parte, apenas cita su genealogía y su escudo de armas 5 .

Respecto a la documentación, sólo se ha tenido acceso a lo publicado que, en este caso es la colección de Huici y Cabanes. El principal problema es que el último volumen editado de la obra hasta la fecha llega al año 1268 y los momentos más importantes de la vida de Fernando Sánchez tuvieron lugar precisamente en los años siguientes ${ }^{6}$.

\section{Infancia y Juventud de Fernando Sánchez}

Nacido en 1241, la noticia principal sobre la ascendencia de Fernando Sánchez de Castro se encuentra en Zurita. El cronista dice que su madre fue una hija de Sancho de Antillón y que era el primero de los hijos naturales de Jaime I, ya que seguía casado el Conquistador con la reina Violante de Hungría $^{7}$. Caso diametralmente opuesto a los hijos que tuvo con Teresa Gil de Vidaure que, por lo general son calificados de bastardos también, algo falso por haberse legitimado su unión por el $\mathrm{papa}^{8}$.

3.- Bernat Desclot, Crònica, vol. II, (ed. Miquel Coll i Alentorn), Barcelona, Barcino, 1987.

4.- No mencionan a Fernando Sánchez de Castro los siguientes grandes cronistas Ramón Muntaner, Crònica, (ed. Joan Francesc Vidal i Jové), Madrid, Alianza, 1970; Juan Fernández de Heredia, Gestas del rey don Jayme de Aragón, Madrid, Sociedad de Bibliófilos Madrileños, 1909. Por su parte, sólo ofrece noticia de la muerte del bastardo real en Carmen Orcástegui Gros, Crónica de San Juan de la Peña, Zaragoza, Institución Fernando el Católico, 1986.

5.- Jerónimo Zurita, Anales de Aragón 1, Libros I, II y III, (ed. Ángel Canellas), Zaragoza, Institución Fernando el Católico, 1998; Jerónimo DE Blancas, Comentarios de las cosas de Aragón, (trad. Manuel Hernández), Zaragoza, Cortes de Aragón, 1995. Similar información ofrece en el estudio clásico Gregorio García CiPrÉs, "Linaje de los Castro”, Linajes de Aragón, 1912, n 11, pp. 270-274.

6.- Ambrosio Huici Miranda y María Desamparados Cabanes Pecourt, Documentos de Jaime I de Aragón, vols. I-V, Zaragoza, Anubar, 1976-1988.

7.- Jerónimo Zurita, Índices de las gestas de los Reyes de Aragón, (ed. Ángel Canellas), Zaragoza, Institución Fernando el Católico, 1984, p. 223: “[...] su hijo don Fernando Sánchez, habido del contubernio con una hija de Sancho Antillón gran hombre de Aragón, a quien llama hijo natural [...]". Pese a que Zurita no indica el nombre de la madre, es conocido que era Blanca de Antillón. La reina Violante, nacida en 1216, se casó con Jaime I en 1235. Murió en 1251.

8.- Para una lectura más sencilla, remitimos a los árboles genealógicos del final. 
Las primeras villas que recibió fueron el núcleo de su señorío, Pomar, Estadilla y Castro, de donde toma el nombre ${ }^{9}$. Hay registro documental de que recibió Pomar en octubre de 1260, cuando contaba con diecinueve años ${ }^{10}$. Sin embargo, llegó a recibir un buen número de poblaciones, tal y como afirmaba Fondevilla, aunque no de manera patrimonial ${ }^{11}$. Una idea que aparece en la bibliografía, ya clásica, es el amor que el rey Jaime I profesó a Fernando Sánchez, algo que a la luz de los documentos no parece sostenible, viendo las donaciones hechas a otros hijos suyos habidos fuera del matrimonio ${ }^{12}$. A Pedro Fernández, cuando tenía diez años lo nombró juez en un caso de Daroca en 1257; a Pedro de Ayerbe le donó las villas de Fanzara y Cullera sitas en el reino de Valencia cuando contaba con un año de edad, el cinco de abril de 1260; Jaime de Jérica obtuvo Eslida, Veo y Ahín, también en Valencia, dos meses más tarde, cuando tenía cinco años ${ }^{13}$. Los dos últimos eran hijos de Teresa Gil de Vidaure quien, sin ser exhaustivos, recibió en nueve años — entre 1252 y 1261 - los castillos y villas de Tarrasa y Jérica, la villa de Alcublas, el castillo y villa de Flix, los castillos de Arcos, Zancarés y Peña

9.- Mariano Badía Buil, Estadilla, cabeza de la baronía de Castro, Barbastro, 1998, p. 89: “Tendría el hijo del rey y de la dama de Antillón aproximadamente la edad de 18 años, cuando Jaime I, para asegurar las finanzas de su bastardo, le dio villas y castillos de Castro, Pomar, Borgamán (sic) y Estadilla".

10.- ACA, reg. 18, fol. 74v., apud A. Huici Miranda y Mª D. Cabanes Pecourt, Documentos de Jaime I, vol. IV, p. 287: "Noveritis nos dedisse dilecto filio nostro, Ferrando Sancii, castrum et villam de Pomar cum omnibus hominibus et feminis [...]". La vez anterior que aparece Fernando Sánchez en uno de los documentos registrados en esta obra es justo un año antes sobre unas rentas concedidas a su favor en Teruel, vid. p. 231

11.- Fernando Fondevilla, "La nobleza catalanoaragonesa capitaneada por Ferrán Sánxez de Castro en 1274", en Congreso de Historia de la Corona de Aragón, vol. II, Barcelona, 1908, pp. 1061-1166, pp. 1073-1074: "En fin, Fernán Sánchez tuvo en honor los pueblos siguientes: Jaca y su término, Alquézar, Nabal, Bespén, Gistau, Valle de Broto, Torla, Ripol, Arcusa, Castellazo, Castellón de Sobrarbe, Morillo, Palo, Trillo, Barcabo, Lorbes, Santa Eulalia de la Peña, Argilers, Ordars, Valle de Portolés, Bestuey, Cireso, Lespuñán, Arahuest, Cornes, Besarán, Cortillas, Valle de Nocito, Sentilló, Isuerre, Ciurana, Llobera, Gordún, Valle de Jaca, Las Bellostas, Canfranc (19 de enero de 1272), rentas de Nabal (19 de septiembre de 1272), Trasmoz (19 de mayo 1274-reg. 23 f. $\left.{ }^{\circ} 81\right)$, Uncastillo, Luna, Aínsa, Ahuesca, Sevil, Alfajarín, Achebles, Ansó, Echo, Triste, Miste, Rompesacos, Santa María, Bencué, Hieste, Biescasán, Sobirón (reg. ${ }^{\circ} 18$ f. ${ }^{\circ}$ 3), Hoz de Jaca, Valle de Sangüesa, Lagunarrota, Lorbes, Barbastro, Valdeportellas, Cireso, Valdenoco, Senticlo (21 de agosto de 1271), Verdún, Lahón, Nueno, Fuentes, San Esteban del Mall, Sádaba, Salas Altas y Salas Bajas".

12.- Vid. en los Anexos el cuadro de los hijos ilegítimos de Jaime I. El tema de la predilección lo afirma María Teresa Ferrer y Mallol, "Los descendientes de Ferran Sanxis de Castre, hijo bastardo del rey Jaime I el Conquistador (siglos XIII-XIV)", Hidalguía, no 122, 1974, pp. 25-48, p. 26: "Ferrán Sanxis fue uno de los hijos preferidos de Jaime I, quien lo demostró dotándole con un patrimonio verdaderamente regio en Aragón, especialmente en el norte de la provincia de Huesca [...]. Constituyó en su beneficio la baronía de Castre y le dio además los lugares cercanos de Olvena y Estadella, asî como Borjamán, Pomar, Jaca y su valle, valle de Broto, Alquézar [...]".

13.- Respectivamente: ACA, reg. 9, fol. 43, apud A. Huici Miranda y M ${ }^{\mathrm{a}}$ D. Cabanes Pecourt, Documentos de Jaime I, vol. III, p. 281; A. Huici Miranda y $\mathrm{M}^{\mathrm{a}} \mathrm{D}$. Cabanes Pecourt, Documentos de Jaime I, vol. IV, p. 256; ibídem, p. 274. 
de Ahija, así como la instalación de una tintorería y el almudín en el alcázar de Valencia que le había dado en su momento ${ }^{14}$.

En resumen, en torno a 1260 todos sus hijos ilegítimos habían recibido alguna merced del rey, pero queda demostrado que Fernando Sánchez, en la documentación consultada, no obtuvo más que sus hermanos. En efecto, hasta 1261 recibió únicamente la villa de Pomar cuando ya era un hombre; mientras que Teresa Gil de Vidaure y sus hijos de corta edad acumulaban como mínimo once lugares otorgados por el rey. Por lo tanto, documentalmente no se puede sostener el tópico del favoritismo de Jaime I hacia Fernando Sánchez.

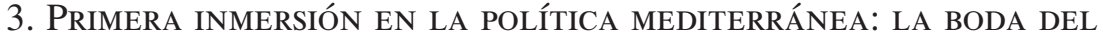 INFANTE PEDRO}

El primer episodio de cierta relevancia recogido en las fuentes que se refiere a Fernando Sánchez es la colaboración en la gestión del matrimonio de su hermanastro el infante Pedro, con Constanza hija del rey Manfredo de Sicilia ${ }^{15}$. En este punto es necesario hacer una recapitulación de los sucesos mediterráneos acaecidos a mediados de siglo XIII.

La política internacional de la segunda mitad del siglo XIII constituye la quiebra de los poderes imperiales en el Mediterráneo: la muerte de Federico II en 1250 y la destrucción del Imperio Latino en $1261^{16}$. A la muerte del hijo de Federico II, Conrado IV, Manfredo — hijo bastardo del primero, hermanastro del segundo- ejerció la regencia de su joven sobrino Conradino.

Tras la defunción de su hermanastro Conrado IV, Manfredo se hizo con cierta facilidad con el control del sur italiano hasta que, aprovechando unos rumores sobre la muerte de Conradino, decidió aprovechar la contingencia que se le presentaba y el 10 de agosto de 1258 se coronó rey de Sicilia ${ }^{17}$.

14.- ACA, pergs. Jaime I, núm. 1304, apud A. Huici Miranda y M ${ }^{\mathrm{a}}$ D. Cabanes Pecourt, Documentos de Jaime I, vol. III, p. 87; ACA, pergs. Jaime I, núm. 1416, apud ibídem, p. 163; ibídem pp. 219 220; ACA, reg. 9, fol. 22, apud ibídem, p. 232; ARV, Real Justicia, t. XXIV, fol. 355, apud A. HuICI Miranda y M ${ }^{\mathrm{a}}$ D. Cabanes Pecourt, Documentos de Jaime I, vol. IV, p. 12; ibídem pp. 299-300.

15.- Véase cuadro genealógico de Federico II Hohenstaufen.

16.- Conrado IV, únicamente Rey de Romanos, parecía fiel epígono de las políticas de Federico II pero murió en 1254. Su hijo, a la sazón nieto de Federico II, sería conocido como Conradino. En 1261 Miguel Paleólogo tomó Constantinopla y se depuso a Balduino II, de manera que el frágil Imperio Latino tocaba a su fin. John Julius Norwich, Breve historia de Bizancio, Madrid, Cátedra, 2000, p. 299.

17.- Steven Runciman, Las Vísperas sicilianas, Barcelona, Reino de Redonda, 2009, pp. 77-84. 
Ante esta situación, Carlos de Anjou, hermano de Luis IX de Francia, aparecía ante los ojos del papado como el paladín que acabaría de una vez por todas con la "raza de víboras"18.

Aunque estaba relativamente seguro en su trono, Manfredo necesitaba apoyos externos para poder mantenerse en caso de que el papa decidiera arrebatarle el reino por la fuerza. Así que, según Zurita, decidió enviar a tres emisarios para gestionar la boda entre su única hija Constanza y el infante Pedro, quien acababa de pasar a ser el heredero de Jaime I a la muerte del infante Alfonso ${ }^{19}$. Tras recibir a los emisarios, en septiembre de 1260 se despachó una embajada de respuesta afirmativa a Sicilia ${ }^{20}$. Varios autores se hacen eco de este suceso, como Desclot y Zurita. El 13 de abril de 1261 el rey Jaime puso al mando de la comitiva a Fernando Sánchez de Castro y a Guillén de Torrella, para ultimar detalles y traer a la joven princesa para su matrimonio con Pedro ${ }^{21}$.

El enlace beneficiaba a ambos monarcas. Manfredo conseguía un firme apoyo mediterráneo que servía de contrapartida al creciente poder angevino que extendía sus tentáculos desde la Provenza hacia Italia, al tiempo que aumentaba su influencia en la corte aragonesa casando a su hija con el heredero. A cambio, Jaime I recibía como nuera a la hija de un bastardo excomulgado por la Iglesia pero, en ese momento, única heredera de un reino importante. Posiblemente, el rey lo valoró como una oportunidad excelente para aumentar sus posiciones marítimas cortadas por el sur y sobre todo por

18.- Previamente la oferta del reino de Sicilia por la Santa Sede fue realizada a Edmundo de Inglaterra quien no tenía ni la capacidad ni el dinero para acometer la empresa. Por el contrario, Carlos de Anjou tenía una posición desahogada y era capaz, tal y como lo había demostrado dominando Provenza, ibídem, pp. 107-122.

19.- J. Zurita, Índices de las gestas, p. 222: "El día 28 de julio por intervención de Guiraldo de Posta, Majoro de Juvenazo y Jacobo Mostacio”. El infante Alfonso murió en 1260.

20.- Jaime I despachó a Raimundo Gaucelm como embajador a Sicilia con plenos poderes, vid. ACA, reg. 11, fol. 226, apud A. Huici Miranda y Ma D. Cabanes Pecourt, Documentos de Jaime I, vol. IV, p. 283

21.- ACA, reg. 11, fol. 241, apud ibídem, p. 304: "Quecumque, enim, super predictis cum dicto illustri rege Cecilie et super facto matrimonii infantis Petri, filii nostri, et domine Constancie, filie sue, duxeritis ordinandum, ratum habere promittimus atque firmum ac eciam illud assecurare, prout melius dictus rex Cecilie vobis, loco nostri, assecurabit”. B. Desclot, Crònica, p. 159: “[...] lo noble rey En Jacme d'Aragó, temès sos misatges al rey Metfré ab II $^{\text {es }}$ naus, los quals misatges foren la I En Ferran Xanxis, frare bort del noble enfant En Pere". No sólo eso, sino que vuelve con la princesa, p. 161: "[Manfredo] El rey aparelà moltres galeres e comnà la donzela a I comte qui avia nom comte Bonifäy e a N Ferran Xanxis [...]". Vid. J. Zurita, Índices de las gestas, pp. 222-223 para el asunto matrimonial al completo. Especialmente interesa en p. 223: "El día 13 de abril estando el rey en Valencia envía a su hijo don Fernando Sánchez [...] acompañado de don Guillén de Torrella a Sicilia para concretar el matrimonio de Constanza hija de Manfredo rey de Sicilia con el infante don Pedro y traer a la nuera con un acompañamiento real". 
el norte tras la firma del tratado Corbeil en 1258. Volcarse hacia el Mediterráneo parecía ser la clave para la ulterior expansión ${ }^{22}$.

Explicados estos sucesos, quedan otros bastante más oscuros. ¿Por qué Jaime I eligió a su hijo ilegítimo Fernando Sánchez, pudiendo haber enviado a los infantes Jaime o Fernando, hijos legítimos que ya tenían edad suficiente como para poder representar a la figura paterna? La diferencia de edad entre los dos era muy reducida y teniendo en cuenta que el infante Jaime se había criado en la corte, parecía ser el más indicado para realizar las gestiones oportunas dictadas por el rey ${ }^{23}$.

Debido a los escasos estudios sobre la bastardía en la Edad Media, no se pueden encontrar otras referencias similares sobre las que hacer alguna comparación. Únicamente existen estudios pero se refieren al siglo XIV, casi 150 años más tarde de las fechas que nos ocupan y para el caso del reino de Navarra ${ }^{24}$. Por eso, sólo se pueden apuntar distintas hipótesis. Algunos autores han querido ver una maniobra de su madre, Blanca de Antillón, para poner a su hijo en puestos de responsabilidad cerca de su padre ${ }^{25}$. Premisa que resulta difícil de sostener debido a que en esos momentos Jaime I estaba amancebado, si no en matrimonio morganático, con Teresa Gil de Vidaure ${ }^{26}$. Sean cuales fueran las causas por las que el Conquistador decidió enviar a Fernando Sánchez de Castro - entre las que la edad, experiencia y legitimidad no parecen ser especialmente importantes-, lo que está claro es que el monarca optó por confiar la misión al mayor de sus bastardos para iniciarlo en la vida pública. No era una tarea difícil una vez decididos los términos, pero no dejaba de ser una responsabilidad importante.

22.- Tampoco es conveniente aventurarse mucho más, pero hay autores que afirman que la expansión por el Mediterráneo, incluyendo Sicilia ya era algo acariciado desde su abuelo, Alfonso II el Casto. Odilio Engels, "El rey Jaime I de Aragón, y la política internacional del siglo XIII" en Jaime I y su época: X Congreso de historia de la Corona de Aragón. Ponencias, Zaragoza, Institución Fernando el Católico, 1974, pp. 213-240, pp. 231-232.

23.- Es bastante lógico pensar que Fernando Sánchez de Castro no fuera criado en la corte sino con su madre, Blanca de Antillón. Respecto a las edades, el bastardo Fernando Sánchez contaba con unos 21 años, 19 el infante Jaime y en torno a 16 el infante Fernando.

24.- María Narbona, "Les bâtards royaux et la nouvelle noblesse de sang en Navarre (fin XIVe siècledébut XVe siècle)" en Alain Marchandisse, Eric Bousmar, y Bertrand Schnerb, (eds.), La bâtardise et l'exercice du pouvoir. Actes du colloque tenu à Liège, 16-17 octubre 2008, (en prensa), pp. $1-15$.

25.- Josep Soler y PALet, "Un aspecte de la vida privada de Jaume I" en Congreso de Historia de la Corona de Aragón, Volumen I, 1908, Barcelona, pp. 536-579, p. 546: "El Sr. Bofarull (A.) sembla suposar al parlar dels temps d'en Ferràn Sanchez, que al 1262 encara mantenía relacions el rey ab la d'Antillón".

26.- Vid. supra nota 14. Además, en toda la recopilación de Huici y Cabanes, Blanca de Antillón no aparece ni una sola vez. 
En retrospectiva, considero lícito pensar que esta primera inmersión en la política mediterránea fue fundamental para la formación del joven Fernando Sánchez y que esta experiencia tuvo que cambiar por completo sus esquemas mentales. Esta argumentación se puede sostener mediante dos líneas, en buena medida opuestas. En primer lugar, fue el encargado de llevar la novia a su hermano; en segundo lugar, salió de la Corona y observó un nuevo entorno cortesano. De esta manera tuvo que ser consciente de que, si bien se le había otorgado una misión de importancia, únicamente actuaba como servidor de Jaime I y de su hermano el infante Pedro. Es decir, su vida estaba estrechamente ligada a lo que ordenasen los que estaban por encima de él. Cabe pensar que el joven Fernando tuvo que quedar deslumbrado con la corte que encontró en Palermo donde, al estilo bizantino, el ceremonial era abrumador y el boato lo ocupaba todo ${ }^{27}$. El círculo áulico siciliano tenía muchos rasgos orientales, como las cortes que se instalaron el Ultramar: el número de riquezas era impresionante, pero lo realmente importante es quién era el señor de todo ello, Manfredo Hohenstaufen. El rey de Sicilia tuvo que causar una honda sensación en Fernando Sánchez, no sólo por sus virtudes sino por los paralelismos que tenía con él ${ }^{28}$.

El rey Manfredo tenía unos diez años más que Fernando Sánchez, seguía siendo joven y — pese a que nadie podría haberlo imaginado — reinaba. Y no sólo eso, sino que como Hohenstaufen, también acariciaba, con legítimo derecho, la idea imperial. Su ascenso se debió a una conjunción de casualidades: sobrevivió a sus hermanastros mayores legítimos quienes ya poseían algún título de importancia ${ }^{29}$ y al encontrarse como miembro de la familia de más edad y poder militar, resultaba el hombre perfecto para tomar el control de la regencia del pequeño Conradino. Fernando, por su parte, también bastardo, joven, tenía un suceso familiar reciente y sugestivo: su hermanastro Alfonso, el heredero de la Corona de Aragón, acababa de morir en 1260. Pudo ver cómo era posible que un bastardo llegara a reinar.

27.- Sobre la corte siciliana desde los Hauteville, S. Runciman, Las Vísperas, p. 46: "En efecto, ni Guillermo I ni Guillermo II salían con frecuencia de su palacio de Palermo, donde llevaban una vida que recordaba más a la de un sultán musulmán que a la de un príncipe cristiano medieval, aunque con un ceremonial conscientemente copiado del hierático estilo de Bizancio". Aplicable también a Federico II y por añadidura, a Manfredo. Walther KöHLER, "Emperor Frederick II., the Hohenstaufe", The American Journal of Theology, volumen 7, no 2 (1903), pp. 225-248, p. 232: "[sobre Sicilia] its enchanted palaces and pleasure-gardens lying about the cities [...]". También en Charles H. Haskins, "Science at the Court of the Emperor Frederick II", The American Historical Review, vol. 27, n 4 (1922), pp. 669-694.

28.- S. Runciman, Las Vísperas, pp. 77-83.

29.- El primogénito, Enrique, había sido rey de Romanos y duque de Suabia. Conrado IV, rey de Romanos, de Alemania y de Jerusalén. 


\section{ENTRE LA LEALTAD Y LA REBELIÓN}

Unos pocos años más tarde de la embajada a la corte siciliana, las crónicas vuelven a ofrecer noticias sobre Fernando Sánchez de Castro. La información la proporciona el propio monarca en el Libro de los hechos. Los moros de Murcia se rebelaron en 1264, de manera que Jaime I se vio moralmente obligado a intervenir en favor de su yerno, Alfonso X de Castilla ${ }^{30}$. Para la campaña necesitaba bastante dinero por lo cual se intentó que se aceptara un impuesto sobre las tierras el bovaje. Una parte de la nobleza y clero lo instaron a reunir cortes. Su hijo natural, Fernando Sánchez, se encontraba entre los que le recomendaron la convocatoria de las mismas. Tras arduas discusiones con la nobleza, a la que se intentaba convencer para que fingiera aceptar el impuesto con el fin de arrastrar al resto de los brazos de las cortes a votar a favor, los nobles acabaron por conjurarse contra el rey ${ }^{31}$. Sin embargo, está documentado en noviembre de 1264 que la nobleza catalana había pagado y que el rey, pese a eximirlos de cualquier prestación no lo hacía del bovaje ${ }^{32}$. Por lo tanto, se pagó al rey; sin embargo éste mandó redactar lo contrario en su Libro para legitimar su postura en el enfrentamiento posterior.

Una facción de la nobleza disgustada, encabezada por Fernando Sánchez, al ver que el asunto se tornaba grave y que no se iba a ceder a favor de los barones, intentó la reconciliación. Los motivos que esgrimió fueron que "el juramento que ellos habían hecho no era contra Nos, sino que era porque incumplíamos sus fueros y les pedíamos cosas inadmisibles y porque [...] les habíamos quitado lo suyo cuando discutían con Nos [...]"33. Al parecer, un juramento los obligaba a cederse las fortalezas entre ellos; de manera que Pomar, villa de Fernando Sánchez, sufrió asedio entre junio y julio de 1265 por parte del rey, pese a haberse reconciliado con su propietario ${ }^{34}$.

30.- JAIME I, Libro de los hechos, pp. 415 y ss. Se relata cómo el rey de Granada comienza a pasar jinetes desde África para hacerle la guerra a Alfonso X, cómo su mujer le pide ayuda a su padre, el rey Jaime I.

31.- Ibídem, p. 426: "Y dijeron a don Jimeno de Urrea que empezase el primero; y él dijo: «En esta tierra, señor, desconocemos el bovaje; y nada más oírlo mentar, exclamaron unánimes que no harían nada»". Cabe destacar que el dicho Jimeno de Urrea era el suegro de Fernando Sánchez y parece que siempre ocupaba uno de los primeros lugares respecto a revueltas y altercados en contra del rey junto con su yerno. En J. Zurita, Anales, pp. 618-625 para una explicación más detallada.

32.- A. Huici Miranda y Mª D. Cabanes Pecourt, Documentos de Jaime I, vol. V, p. 138: “[...] per nos et nostros, recognoscimus et confitemur vobis, richis hominibus et militibus Cataloniae quod subsidium sive servitium quod nobis gratis et spontanea voluntate, et amore maximo, ac puro et gratuito dono, et ad preces nostras, in auxilium guerrae quam contra Sarracenos proponuimus habere [...]".

33.- JAIME I, Libro de los hechos, p. 434.

34.- Ibídem, p. 435. Aunque no se dice que se entregaran los castillos entre los coaligados, se puede inducir que era así debido a que Pomar de Cinca era patrimonio del bastardo y éste ya se había reconciliado con su padre. Por otra parte, en la posterior rebelión de la nobleza, se hace eso mismo tal y como lo cuenta el rey. 
La campaña en ayuda del rey de Castilla no podía esperar, así que el asunto se dejó en manos de los obispos de Zaragoza y Huesca, cuyas gestiones no fueron satisfactorias en absoluto; tras finalizar la guerra en el sur, los problemas retornaron. En esta ocasión, el ricohombre Ferriz de Lizana desafió al monarca, quien respondió asediando su villa. Casualmente, pese a la reconciliación que se ha citado más arriba, Fernando Sánchez sostenía una posición un tanto ambigua, colaborando con tropas en el castillo de Lizana. Mediante la toma del castillo y ahorcando a sus defensores aparentemente se puso punto final a la disensión nobiliaria.

\section{Entre la Séptima y la Octava CrUZada: la expedición a Tierra SANTA}

Una vez disuelta la coalición de la nobleza, Jaime I comenzó a proyectar una expedición a Tierra Santa que en buena medida no dejaba de ser un tanto quimérica ${ }^{35}$. Lógicamente, ser el príncipe de mayor autoridad de la Península y haber recibido emisarios orientales, así como promesas de ayuda de las órdenes militares excitó sobremanera al monarca ${ }^{36}$. Todo ello vino agrandado por las recientes embajadas armenias, tártaras y bizantinas que lo animaban a atacar a los mamelucos. Una vez resueltos los preparativos, la flamante escuadra soltó amarras del puerto de Barcelona en septiembre de 1269 y se hizo rumbo a Ultramar, para deshacerse pocos días después por una tempestad ${ }^{37}$. La parte principal de la armada al mando del rey, regresaba

35.- Algunos autores tienen una visión bastante crítica con la expedición del rey, donde se ve prácticamente una especie de alarde o que simplemente superó a Jaime I. S. M. Cingolani, Historia y mito, p. 406: "Todo el relato de la fallida empresa gira en torno a la voluntad divina, como si él, esta una vez en su vida, no tuviera capacidades propias [...] Ahora no parece estar seguro [...] y se aferra a la voluntad de Dios". En absoluto lo vio así J. Zurita, Anales, p. 672: "Era la armada de treinta naos gruesas y algunas galeras, e iban en ella más de ochocientos hombres de armas, gente muy escogida y las mejores compañías de almogávares y ballesteros, y los maestres del Temple y del Espital, el obispo de Barcelona, el comendador mayor de Alcañiz don Galcerán de Pinós, el sacristán de Lérida que después fue obispo de Huesca, don Fernán Sánchez y don Pedro Hernández, sus hijos, don Jimeno de Urrea, don Pedro de Queralt y otros ricos hombres y caballeros hasta número de trecientos".

36.- JAime I, Libro de los hechos, p. 488: "Estando Nos en Valencia, recibimos a Jaime Alarich con los tártaros y a otro mensajero de Grecia que estaba allí. Y nos dijeron de parte del gran kan, que era rey de los tártaros, que tenía la intención y voluntad de ayudarnos, que fuésemos a Alayaz o a otro lugar y que él saldría a vernos, y que en su tierra encontraríamos todo lo que necesitáramos; y así, gracias a su ayuda, podríamos conquistar el santo Sepulcro. Añadía que él nos proporcionaría máquinas bélicas y nos abastecería de víveres. El otro mensajero, del Paleólogo, emperador de los griegos, nos dijo que él nos enviaría provisiones por mar".

37.- Steven Runciman, Historia de las Cruzadas, Madrid, Alianza Editorial, 2008, p. 857: "El 1 de septiembre de 1269 el rey Jaime I de Aragón zarpó de Barcelona con una poderosa escuadra para rescatar Oriente". Para los detalles del propio rey en JAIME I, Libro de los hechos, pp. 489-490. 
a casa mientras que una parte menor llegó a San Juan de Acre. Estas naves estaban al mando de Fernando Sánchez de Castro y de Pedro Fernández de Híjar, ambos hijos naturales del rey ${ }^{38}$.

Jaime I decidió llevarse a dos hijos ilegítimos a la expedición de Palestina como toda representación familiar. Mientras a la Octava Cruzada marcharon juntos el rey de Francia, el de Navarra y el de Sicilia rodeados de lo mejor de sus reinos, el Conquistador resolvió llevar a cabo su aventura particular con los dos bastardos. En este caso, ante el silencio de las fuentes consultadas por tal suceso, cabe pensar que los acontecimientos previos marcaron la decisión: era necesario separar a Fernando Sánchez de la nobleza del reino que tantos problemas había causado y de la cual había sido su portavoz.

Otro aspecto a tener en cuenta en esta expedición es la persona del propio Jaime I, que a la sazón contaba con 61 años y se encontraba en la cumbre de su prestigio, sobre todo tras haber socorrido a Alfonso $\mathrm{X}$ en el reino de Murcia. Por esto mismo, es posible que el monarca aragonés pensara en el viaje a Ultramar como su último proyecto vital ${ }^{39}$. Ha de tenerse en cuenta que el periplo podía ser peligroso y no muchos volvían de Tierra Santa con su edad ${ }^{40}$.

De todas formas, la estancia de los dos hermanastros en el Medio Oriente no se prolongó en exceso ya que, el mayor decidió volver a casa dejando a Pedro al mando del puñado de hombres que quedaban de la expedición inicial en $\mathrm{Acre}^{41}$. Sobre los motivos del temprano regreso, tanto las fuentes como la bibliografía consultadas guardan silencio.

38.- Ibídem, p. 857: "Sólo una pequeña escuadra, al mando de los dos bastardos del rey, los infantes Fernando Sánchez y Pedro Fernández, prosiguió la marcha. Llegaron a Acre a finales de diciembre, ansiosos de luchar contra el infiel". J. ZuRITA, Índices de las gestas, pp. 231-232: "El día 5 de septiembre el rey sale con su armada de Barcelona, y casi destruida por la tempestad, se refugia en el puerto de Aguas Muertas y viéndose ya viejo [...] desistió de la expedición a Jerusalén. Pero sin embargo el almirante don Pedro Fernández y don Fernando Sánchez, hijo del rey, manteniendo el curso firme de las naves llegaron a Palestina".

39.- El propio rey narra cómo sus hijos y vasallos le desaconsejan el viaje y le ruegan encarecidamente que no marche en JAIME I, Libro de los hechos, pp. 488-489: "Entonces nos mandó un mensaje la reina de Castilla diciéndonos que nos viésemos con ella; y vino a Huerta con sus hijos. Vinieron también nuestros hijos, el infante don Pedro, el infante don Jaime y el arzobispo de Toledo - hijo nuestro-, y durante dos días nos rogaron, llorando y suplicándonos, que nos quedásemos. Pero de ningún modo pudieron conseguir retenernos".

40.- Con similar edad y previo a Jaime I es el caso del emperador Federico I Barbarroja, muerto con casi setenta años camino a la Cruzada. Al año siguiente de la expedición a Ultramar, Luis IX de Francia moriría cerca de los 60 .

41.- Francisco CARreras y LANDI, "La Creuada a Terra Santa 1269-1270”, en Congreso de Historia de la Corona de Aragón, vol. I, pp. 106-138, p. 121: "L'infant bastart Ferràn Sanxis s'en tornà y l'altre infant Pedro Ferrandiç prosseguí de capitost a Acre". 


\section{La Situación del Mediterráneo En la décAda de 1260}

Para comprender cómo transcurrió el regreso del viaje de Fernando Sánchez a la Península Ibérica, considero necesario hacer un breve inciso para centrar la atención en el escenario, el Mediterráneo, y los protagonistas, Manfredo, Carlos de Anjou y Jaime I.

Ramón Berenguer V de Provenza — primo de Jaime I — había muerto sin descendencia masculina en 1245, de tal manera que su hija pequeña, Beatriz, era la heredera de sus posesiones. Estaba casada con Carlos de Anjou, quien, de esta manera, consiguió ampliar su patrimonio considerablemente. Pese a sufrir durante varios momentos de su gobierno rebeliones de los provenzales, el angevino tuvo estos territorios como base para su posterior expansión mediterránea. Como consecuencia, Jaime I se sentía ofendido por no haber sido consultado por la herencia del condado. Por este motivo, Carlos de Anjou recelaba de las políticas aragonesas que podrían aprovechar algún momento crítico para la intervención armada ${ }^{42}$. Aunque esto no afectaba directamente a sus posesiones, el infante Pedro también estuvo a punto de hacerse con el control de Tolosa, ciudad que en 1271 lo reclamaba como señor, amenazando las posiciones angevinas en Provenza ${ }^{43}$.

Poco antes de que el rey Jaime I abrazara la cruz en 1269, Carlos de Anjou había conseguido eliminar a los últimos Hohenstaufen: a Manfredo en 1266, y dos años más tarde al joven Conradino ${ }^{44}$. Mediante la violencia se consiguió un traspaso de poder en el reino de Sicilia y prácticamente en dos terceras partes de la Península Itálica. Pero la ambición del angevino no se detuvo ahí, ya que las posibilidades de expansión eran amplias a costa de los pequeños estados balcánicos que habían sobrevivido al desastroso Imperio Latino - incluyendo el recién restaurado Imperio Bizantino- por su atomización. A lo largo de la década de 1270, Carlos de Anjou fue adquiriendo títulos y posesiones de cierto valor, como los reinos de Albania y Jerusalén, que pretendía usar de base para su gran salto sobre Bizancio.

42.- Ibídem, p. 137: "A principios de 1262, cuando Carlos había ido al norte a visitar las tierras de Anjou y a discutir con su hermano la posible oferta del trono siciliano, surgió un nuevo levantamiento en Provenza. Bonifacio de Castellane volvió a agrupar a la nobleza y los marselleses se levantaron contra los funcionarios franciots y los expulsaron. Génova prometió apoyar a los rebeldes y los hijos del rey de Aragón esperaban en Montpellier, dispuesto a aumentar las dificultades de Carlos con su intervención”. Hay que tener en cuenta que el abuelo de Jaime I, Alfonso II había sido también marqués de Provenza.

43.- J. Zurita, Índices de las gestas, p. 234.

44.- En la batalla de Benevento al primero y en la de Tagliacozzo al segundo. 
El infante Pedro, heredero de Jaime I, se había casado con Constanza Hohenstaufen, hija y heredera de Manfredo rey de Sicilia. Y pese a que el Papa había concedido el reino a Carlos de Anjou, Pedro no dejaba de pensar que se le había arrebatado lo que por justicia era de su mujer y en consecuencia, suyo también. Se añadía el hecho de que tras la muerte de los últimos Staufen, partieron al exilio un buen número de notables que se reunieron alrededor de la legítima heredera, Constanza. Así las cosas, se puede retomar el periplo de regreso a casa del protagonista del artículo.

\section{En los límites de la obediencia: entrevista con Carlos de Anjou}

Tras analizar la tensa situación del Mediterráneo occidental, condicionada principalmente por las ambiciones de Carlos de Anjou y Jaime I de Aragón, volvamos ahora a la figura de Fernando Sánchez. En las crónicas se recogen noticias que señalan que a su retorno de San Juan de Acre hizo escala en el reino siciliano para entrevistarse con Carlos de Anjou. Pese a que ciertas puntualizaciones de Desclot han de ser tomadas con precaución, todo parece indicar que, junto con su suegro Jimeno de Urrea, se entrevistó con el nuevo rey de Sicilia, el de Anjou:

"[...] En Ferran Xanxis e $N$ Examèn d'Orrea son sogre, Ia vegada que venien d'Oltramar per terra de la ila del Cret ençà, se giraren al rey Karles e parlarenab él, per ço cor sabien que era el major enemich que l'enfant En Pere avia" ${ }^{45}$.

"Don Fernán Sánchez y don Jimeno de Urrea [su suegro] volvieron por la isla de Creta y a la vuelta tocaron en Sicilia donde vieron al rey Carlos del cual fueron muy bien recibidos y festejados; y según en algunos anales parece recibió don Fernán Sánchez caballería de mano del rey por lo cual se siguieron grandes celos y de ellos un implacable odio y discordia entre él y el infante don Pedro su hermano" ${ }^{46}$.

Este punto es de gran importancia dentro de la historia de Fernando Sánchez. Sorprende que a su edad no hubiera sido armado caballero ${ }^{47}$. Pero las crónicas guardan silencio al respecto. Realmente lo importante es el hecho en sí, porque como se ha argumentado anteriormente, el infante Pedro y su esposa estaban interesados en la adquisición de Sicilia, algo que quizás ya formara parte de la política dinástica; no cabe duda de que la entrevista de

45.- B. Desclot, Crònica, pp. 18-19.

46.- J. Zurita, Anales, p. 673.

47.- Fernando Sánchez de Castro rondaría los treinta años. 
Fernando y su sumisión al rey Carlos al ser armado caballero por éste iba en contra de los intereses reales. Pese a que ha de tenerse cierta precaución en las observaciones de Desclot respecto a lo que habló Fernando Sánchez con el de Anjou, muy posiblemente fuera la sustitución de la rama legítima de Aragón por la bastarda ${ }^{48}$. Aún así, hay un punto al que no se ha podido dar respuesta: ¿por qué se hizo armar caballero por Carlos, enemigo de los intereses aragoneses y luego regresó? Bien pudiera ser que fuera una invención posterior elaborada por el círculo de Pedro III, como Desclot y repetida por cronistas como Zurita.

Llegados a este punto, es necesario señalar que la bibliografía se declara abiertamente a favor o en contra de nuestro personaje. Ya desde los propios cronistas que como se ha visto en el caso de Desclot, se tenía claro el complot supuestamente urdido por Carlos de Anjou y Fernando Sánchez ${ }^{49}$.

Es muy difícil determinar si realmente existió tal confabulación. Hay argumentos que avalan esta teoría que aunque pudiera haber sido inventada por los partidarios del infante Pedro, bien podría tener un poso de verdad. Es cierto que el futuro heredero de la Corona, gracias a su matrimonio y sus ambiciones

48.- B. Desclot, Crònica, p. 19: "El rey Karles aculí-los molt bé, e donà-lur grans dons e tractá ab éls que deguessen alciure 1'enfant En Pere ho gitar de la terra, e que En Ferran Xanxis fos rey d'Aragó [...]" Autores de principios del siglo XX, en una postura de admiración por el bastardo, llegaron verter suposiciones aún más arriesgadas, como F. Fondevilla, "La nobleza catalanoaragonesa", p. 1081: "Este mismo Carlos de Anjou fué el que comprendió, penetrándola, la valía política y militar de Ferrán Sánchez”. En páginas siguientes llega incluso a decir que Clemente IV quería que el regio bastardo fuera el encargado de gestionar la recuperación de los Santos Lugares.

49.- María del Carmen Palacín Zuera, Pomar de Cinca. Retazos de su historia, Huesca, 2004, p. 105 "[...] en estas enérgicas suyas, la réplica a los más íntimos deseos del bastardo, porque nadie dudó entonces (ni podemos dudar ahora) que Fernán Sánchez preveía y deseaba la suplantación del infante Pedro, o al menos su sustitución por el infante Jaime o por otro de los hijos legítimos de Jaime I, el rey". Además, se retrotraen precisamente estas ambiciones a la famosa entrevista que mantuvo con el rey Carlos, p. 112: "Es un hecho que el bastardo, desde el momento en que había tenido tratos con Carlos d'Anjou, era un peligro para los reinos de la Corona de Aragón". Una visión diametralmente opuesta encontramos en una corriente historiográfica algo caduca, pero no deja de tener cierto interés en F. Fondevilla, "La nobleza catalanoaragonesa", p. 1083: [...] el Infante Pedro para apartar el espectro de un futuro contrincante, no dudó en apelar a la injuria y atribuyó a su hermano bastardo designios y ruindades que el de Castro estuvo siempre muy lejos de acariciar". Continúa, ya con un carácter mucho más emotivo, p. 1090: "Ferrán Sánchez es digno de Aragón. Es un héroe". Evidentemente, sostener una visión muy positiva del bastardo conlleva una muy negativa del infante Pedro. Desclot ya hemos señalado que cita la alianza con Carlos de Anjou para hacerse rey de Aragón. Por su parte, en J. Zurita, Índices de las gestas, pp. 234-235: "[...] estaba persuadido que había conspirado con los nobles para arrebatarle el reino, con las esperanzas infundidas a Fernando por el rey Carlos de Sicilia [...]" El mismo autor se muestra más contundente con sus apreciaciones en los Anales; J. Zurita, Anales, pp. 693-695. Aquí achaca la enemistad del infante y el bastardo, al vasallaje que le rindió Fernando Sánchez a Carlos de Anjou. Por ello, y por un posible pacto para heredar las posesiones aragonesas a la muerte de Jaime I. 
personales, constitutía una amenaza tanto en el Mediterráneo como en los señoríos meridionales angevinos. También es importante reconocer que el de Anjou buscaba a toda costa construir un nuevo estado similar al Imperio Latino que añadir a su patrimonio y para ello necesitaba tranquilidad en el occidente mediterráneo. Teniendo en cuenta que Fernando Sánchez ya había sido en su momento representante de los nobles descontentos, siempre apoyado por su suegro Jimeno de Urrea, podría volver a levantarse en armas. Hay que tener en cuenta otro hecho que considero clave y que posiblemente lo animara a poner en marcha sus proyectos: la referida entrevista con Manfredo un decenio atrás. A mi modo de ver hay motivos suficientes para que estos dos personajes intentaran un cambio de poder en Aragón. Parece verosímil que Carlos de Anjou estaba interesado en que Fernando Sánchez "fos rey d'Aragó". Y el propio bastardo, también.

\section{La Rebelión nobiliaria y Fernando Sánchez de Castro}

La situación en la Corona también estaba abonada convenientemente para, si no dar un golpe de estado en toda regla como parece que era la trama "oficial", forzar al rey a doblegarse a las exigencias nobiliarias. El descontento de la nobleza se puede ver reflejado en los problemas crecientes entre el infante Pedro y Fernando Sánchez, entre los que el rey acabó viéndose involucrado. De hecho, el clímax de la tensión se alcanzó en el momento en el que el bastardo regio acusó, a principios de 1272, a su hermanastro de un intento de asesinato, suceso que el propio rey registró en su Libro de los hechos. Al parecer, Pedro buscaba la eliminación de Fernando Sánchez, una vez descubierta la conjura con Carlos de Anjou.

En un principio, Jaime I no supo cómo abordar el asunto, ya que se trataba del manifiesto odio personal entre su primogénito y su bastardo; tras realizar las pesquisas pertinentes tomó partido por Fernando y privó al infante Pedro de la Procuración de Aragón y Cataluña ${ }^{50}$. El Conquistador intentaba llegar a una especie de reconciliación que acabó siendo imposible porque el heredero reveló una trama de intento de asesinato de su persona así como movimientos

50.- J. Zurita, Índices de las gestas, pp. 234-235: "Pedro maquina la muerte de su hermano, como de un enemigo, porque esta persuadido que había conspirado [...]. Don Jimeno de Urrea, hombre de mucho poder, ayuda en todo a don Fernando Sánchez oprimido y desesperado". JAIME I, Libro de los hechos, pp. 506-507: "Al irnos de Valencia, pasamos por Sagunto, donde recibimos a un hombre de Fernando Sánchez de Castro con una carta suya. Nos decía en la carta que el infante don Pedro había ido a Burriana para matarlo, pues lo habían buscado debajo de la cama con espadas y por un pasadizo que había en la casa $[. .$.$] ".$ 
de agitación y subversión por parte del bastardo, principalmente en Aragón ${ }^{51}$. Acusaciones a las que los nobles implicados se negaron a contestar. ¿Hasta qué punto esto era cierto, teniendo en cuenta que a la postre los vencedores fueron el rey y el infante?

A principios de 1273 , el rey había decidido socorrer una vez más a su yerno, Alfonso X de Castilla, contra el reino de Granada. Para ello reunió sus mesnadas, pero el vizconde de Cardona y varios nobles más se negaron a acompañarlo porque según ellos no tenían obligación de hacerlo ${ }^{52}$. Pese a estos problemas, el monarca marchó al Concilio Lyon II donde fue el único príncipe que asistió. A su retorno a finales de 1274 se encontró un panorama más revuelto aún, pese a que en la distancia había intentado solucionarlo. Debido a que el infante Pedro había determinado incautar un feudo de una forma no lícita a los ojos de los barones, por este motivo se desencadenó una unión de los nobles para defender sus derechos (pese a que el rey les había dado la razón en un principio) ${ }^{53}$. Mientras, el rey intentaba dar castigo al de

51.- Ibídem, p. 510: “[...] Fernando Sánchez ha hecho tales cosas contra vos que no debéis interceder ni tenéis que querer que él lo perdone. Ha dicho, por ejemplo, que vos no debéis reinar e intentó envenenar al infante $y$, con ricohombres y altos ciudadanos, ha pretendido alzar vuestra tierra en vuestra contra. Esto se demostrará en su lugar y momento. Pues en esta reunión habían intervenido, entre otras personas, ricohombres; en su mayor parte, de Aragón". Si bien ve que hay bastantes rumores, da por claro y bueno Zurita que había un pacto entre el bastardo y Carlos de Anjou, J. Zurita, Anales, p. 693: "Tuvo principio su enemistad, allende que don Fernán Sánchez en las alteraciones pasadas había seguido la opinión y querella de los ricos hombres del reino contra el rey su padre, porque se dio a entender al infante que su hermano tenía puesta grande amistad con Carlos rey de Sicilia su capital enemigo, y que de su mano había recibido la orden de caballería para más obligarse en su ofensa. Y refiere Aclot - autor antiguo que escribe las cosas de aquellos tiempos- que le fue persuadido que tenían trato de matarle o echarle de la tierra con promesa que Carlos había hecho que ayudaría y daría favor a don Fernán Sánchez, para que sucediese en el reino".

52.- Ibídem, p. 703: "Llegando el rey a Lérida vino a él el vizconde de Cardona; y el rey le rogó que le siguiese para servirle en la guerra que pensaba hacer del reino de Valencia contra los moros en favor del rey de Castilla; y excusándose el vizconde con buenas palabras, el rey le mostró en pública corte en aquella ciudad por los instrumentos de los feudos y por el honor que el vizconde tenía del rey, que era obligado de servirle a donde quiera que el rey quisiese; mayormente que por tenor del usage de Barcelona, era obligado de asistir al rey en sus huestes y cortes y seguirle en las jornadas en que él fuese en persona, como él y sus antecesores los vizcondes de Cardona lo habían acostumbrado. Lo mismo requirió el rey a Pedro de Bergua, don Galcerán de Pinós, don Guillén de Castelaulí y Maimón de Castelaulí, don Berenguer de Cardona y don Guillén de Rajadel”. Ramón Folch de Cardona ya había dado problemas en su momento en 1268 por sus intereses en el condado de Urgel a la muerte de su titular, Álvaro de Cabrera (vid. pp. 665-666). Para una relación de los problemas que causó durante el reinado de Jaime I, son buenos indicadores todos los documentos referidos al vizconde y al rey en A. Huici Miranda y $\mathrm{M}^{\mathrm{a}}$ D. Cabanes Pecourt, Documentos de Jaime I, vol. III, pp. 77, 99, 115; ibídem, vol. IV, pp. 235, 243; ibídem, vol. V, pp. 77, 279 y ss., 292.

53.- JAime I, Libro de los hechos, p. 530. Para el antecedente del pleito, p. 472. J. Zurita, Anales, p. 693: "Después de haber declarado el infante su ánimo contra su hermano y que le procuraba la muerte, don Fernán Sánchez se confederó con algunos barones de Cataluña que se tenían por maltratados y agraviados del infante; porque siendo lugarteniente general había procedido rigurosamente contra algunas personas principales que traían alterada la tierra y hacían mucho daño y estrago en ella, y había 
Cardona, haciéndole devolver todos sus feudos, algo a lo que el vizconde se negó ${ }^{54}$, las hostilidades acabaron estallando de manera abierta entre el rey y el infante por un lado, la nobleza y el bastardo por el otro ${ }^{55}$.

Los nobles rebeldes se aliaron con Fernando Sánchez y con algunos castellanos para hacer frente común contra el rey Jaime $\mathrm{I}^{56}$. Aunque éste en su Libro de los hechos no es nada prolijo en dar información sobre lo que fue una auténtica rebelión de lo más granado de la nobleza, Zurita sí facilita más detalles:

"Sucedió por este mismo tiempo que el vizconde de Cardona y don Fernán Sánchez y don Artal de Luna y algunos otros ricos hombres de Aragón se vieron en el reino de Castilla y se confederaron y juramentaron entre sí; y volvieron con don Fernán Sánchez a Estadilla, a donde se hicieron ayuntamientos de gentes de este reino. Entonces se juntaron también algunos barones de Cataluña en Ager, con sus compañías, y eran el vizconde de Cardona y los condes de Ampurias y Pallás [...]"57.

Obviando el largo elenco de nobles que se enumeran, hay un detalle que conviene destacar: la villa de Estadilla ejerció como núcleo desde donde se dirigió la revuelta. Y consta que Fernando Sánchez era el señor de la población. Se subraya así el hecho de que el regio bastardo era el líder visible de la rebelión, y probablemente también uno de los cerebros que la habían maquinado. Finalmente los aragoneses acabaron por sumarse a los catalanes y decidieron desnaturalizarse del rey, pese a los intentos de Jaime I por sol-

mandado anegar a Guillén Ramón de Odena, hombre de gran linaje. Y con el favor de don Jimeno de Urrea suegro de don Fernán Sánchez que era muy poderoso, siguieron a don Fernán Sánchez algunos ricos hombres y caballeros aragoneses que todavía proseguían su querella, pretendiendo que el rey los tenía desaforados y los había desheredado, ocupándoles los lugares que tenían en honor; y sobre esto recibieron homenajes los unos de los otros y se comenzaron de alborotar en forma de guerra".

54.- JAIME I, Libro de los hechos, p. 532: "Nos insistimos en que la cosa estaba clara: ellos tenían los feudos por Nos, Nos les habíamos mandado servirnos y ellos no lo habían querido hacer, por lo cual se los habíamos quitado. Y como ya estaba sentenciado, no hacía falta un nuevo juicio ni podían conseguir otra cosa de Nos".

55.- Ibídem: "Cuando vieron que no podían conseguir nada más, se desnaturalizaron de Nos y del infante don Pedro, hijo nuestro. Y antes de haber transcurrido el plazo para la ruptura con Nos, fueron a Figueras, que era del infante don Pedro, y prescindiendo de la formalidad de acatar el derecho, quemaron la villa y la destruyeron totalmente [...]". J. ZuriTA, Anales, p. 706: "El vizconde, visto que el rey con tanta insistencia pedía los castillos que tenía en feudo, determinó de darlos, exceptuando los castillos de Cardona, Castelaulí y Zatalla, pretendiendo que no era obligado de entregarlos. Y ésta fue la causa de la guerra que se movió poco después entre el vizconde de Cardona y los barones de Cataluña con el rey y con el infante don Pedro su hijo".

56.- Ibídem, p. 719: "Pero entendióse que mañosamente andaban dilatando y entreteniendo el tiempo hasta confederarse con don Fernán Sánchez hijo del rey y con algunos ricos hombres de Aragón y Castilla, como lo hicieron".

57.- Ibídem, pp. 727-728. 
ventar el conflicto por la vía diplomática. Los motivos que expusieron los rebeldes aragoneses fueron principalmente el agravio constante y el ataque de los vasallos del infante Pedro a los clientes de Fernando Sánchez: tanto a sus hermanos por parte de madre, como a otros afectos a él, (Jimeno de Urrea, Pedro Cornel...).

Así la situación, Jaime I dio su beneplácito para el inicio de las hostilidades. En Aragón se encargó personalmente de ello el infante, mientras que el anciano monarca intentaba poner orden en las tierras catalanas. ¿Por qué adoptó esta decisión y no al revés? Considero que la elección de Jaime I fue pragmática. El reino estaba al borde de la anarquía y él posiblemente no se veía con fuerzas para ejercer una justicia que había de ser severa con su díscolo hijo. Con este proceder se aseguraba el éxito de la eliminación de Fernando Sánchez definitivamente.

El desenlace final de la historia de Fernando Sánchez de Castro tuvo lugar precisamente en las cercanías de su señorío. De camino a Antillón se vio sorprendido por las tropas del infante de manera que se acabó refugiando en Pomar de Cinca. El castillo de la localidad fue cercado y, pese a su intento de huida vestido de pastor mientras uno de sus hombres se disfrazaba con sus ropas, fue descubierto. El infante Pedro lo mandó ahogar en el Cinca ${ }^{58}$.

Hasta hace un par de años se desconocía el paradero exacto de los restos de Fernando Sánchez. S. M. Cingolani apuntaba, con acierto, lo que las últimas investigaciones han revelado. ${ }^{59}$. Pese a que Ricardo del Arco barajaba distintas posibilidades, que incluía su estancia en Santes Creus, lo más seguro era que su sepulcro estuviera en Santa María de Fonclara ${ }^{60}$. Esta decisión sería tomada por la cercanía, ya que está situada a 15 kilómetros de Pomar de Cinca, núcleo central del feudo de Fernando Sánchez ${ }^{61}$.

58.- J. Zurita, Anales, pp. 749-752 se detallan todos los acontecimientos, siendo el infante Pedro severamente criticado por su falta de piedad hacia su hermanastro. JAIME I, Libro de los hechos, p. 536: "Pero antes de que nos fuésemos de aquí nos llegó la noticia de que el infante don Pedro, sitiando un castillo de Fernando Sánchez, lo había cogido y lo había hecho ahogar. Cuando lo oímos, nos alegramos por ello, pues era algo muy grave que él, que era nuestro hijo, se hubiera alzado contra Nos, habiéndole hecho Nos tanto bien y tras haberlo beneficiado notablemente".

59.- Stefano M. Cingolani, "Fernando, abad de Montearagón, y Fernando Sánchez, hijos de Jaime I, y el monasterio de Santes Creus", Aragón en la Edad Media, no 23 (2012), pp. 39-65.

60.- Ricardo Del ArCo y GARAY, Sepulcros de la Casa Real de Aragón, Madrid (2012), Instituto Jerónimo Zurita, 1949, p. 208. De cualquier manera, la idea de Santes Creus viene de principios del siglo XIX pero supone un dislate histórico. ¿Iba a enterrarse Pedro III con su hermanastro al que él mismo había mandado dar muerte?

61.- S. M. Cingolani, "Fernando, abad de Montearagón”, p. 64. Sobre el devenir de sus señoríos una vez muerto, vid. Ana Isabel Lapeña Paúl, "La baronía de Castro y el molino de Estadilla", Homenaje a Don Antonio Durán Gudiol, Huesca, Instituto de Estudios Altoaragoneses, 1995, pp. 515-529. 
En efecto, la investigación de R. Pablo ha revelado unos documentos en los que el propio Fernando Sánchez pedía, antes de partir a Tierra Santa, ser enterrado en Fonclara. Tras su muerte, los monjes reclamaron su cuerpo al Temple, orden que había custodiado sus restos en Monzón ${ }^{62}$.

\section{Conclusiones}

Como ha quedado patente, las fuentes cronísticas disponibles para elaborar una biografía de Fernando Sánchez de Castro son bastante limitadas. Únicamente ofrecen datos sobre sucesos muy concretos de su vida, relacionados con la boda de su hermanastro y la primera visita a Sicilia, los escarceos con la nobleza levantisca, la expedición a Tierra Santa y la entrevista con Carlos de Anjou, su rebelión y muerte.

Una primera lectura de su vida, sobre todo atendiendo al Libro de los Hechos, apunta claramente a los problemas que el rey tuvo con su hijo y parece que se trata únicamente de un problema interno. Pero ha quedado demostrado que la política exterior tuvo un peso fundamental en dichos conflictos. Es cierto que no los suscitó, pero la carga ideológica que había ido adquiriendo Fernando Sánchez a lo largo de su vida, sobre todo a su paso por el reino de Sicilia, fue fundamental: primero con Manfredo, cuando descubrió que un personaje secundario y bastardo como él podía llegar a adquirir un reino; segundo con Carlos, quien muy posiblemente lo espoleó para dar rienda suelta a sus ambiciones y servir a sus propios intereses.

Lo notorio del caso es que la política mediterránea, pese a los problemas de las distancias y comunicaciones, era muy fluida y los intereses orientales podían incidir de forma sustancial en sucesos acontecidos en el otro extremo. Poco después de los hechos anteriormente apuntados, Carlos de Anjou padecería las Vísperas sicilianas.

De cualquier manera, y a la falta de otros estudios que serían interesantes para ir llenando este vacío historiográfico, se puede afirmar que el papel de este personaje fue cercano al rey y que por lo general estuvo muy relacionado con hechos de armas. Encarna el papel de milites a la perfección, sea al servicio de la Corona o como caudillo de los nobles rebeldes; es ante todo un

62.- Rafael Pablo Reimat, «La sepultura de Fernán Sánchez de Castro y el monasterio de Fonclara», CEHIMO, no 39 (2013), pp. 39-60, p. 51: «Como se ha demostrado en este trabajo, el cadáver de Fernán Sánchez de Castro fue recogido en el río Cinca, cerca de Pomar, por los templarios de Monzón y sepultado en la iglesia de su castillo. Allí permaneció unos 27 años, siendo trasladado después, según todos los indicios señalados, al monasterio de Fonclara en cumplimiento de su última voluntad.» 
guerrero. Además, su padre —igual que hizo con el resto de hijos-intentó en la medida de lo posible insertarlo dentro de la nobleza, otorgándole señoríos como la baronía de Castro y casándolo con una persona de alcurnia, la hija de Jimeno de Urrea.

Lo singular de este caso es que fue el único de los hijos de Jaime I que se rebeló contra él y posiblemente por ello se dispone más información sobre Fernando que sobre los otros ilegítimos, que también tuvieron responsabilidades cercanas al monarca. Sin embargo, no cataron las mieles sicilianas ni el dulce sabor del poder.

\section{AneXos 63}

Hijos legítimos de Jaime I:

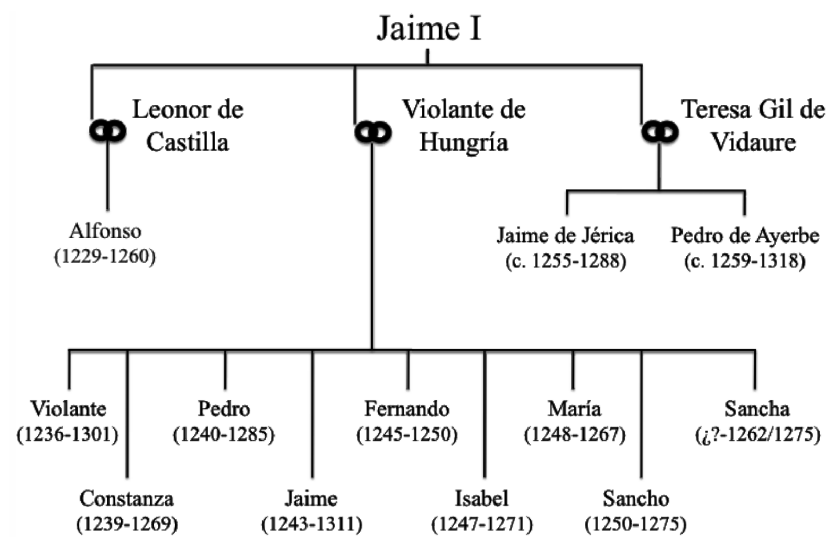

63.- Los dos circulitos implican matrimonio. La línea discontinua marca ilegitimidad. 
Hijos ilegítimos de Jaime $\mathrm{I}^{64}$ :

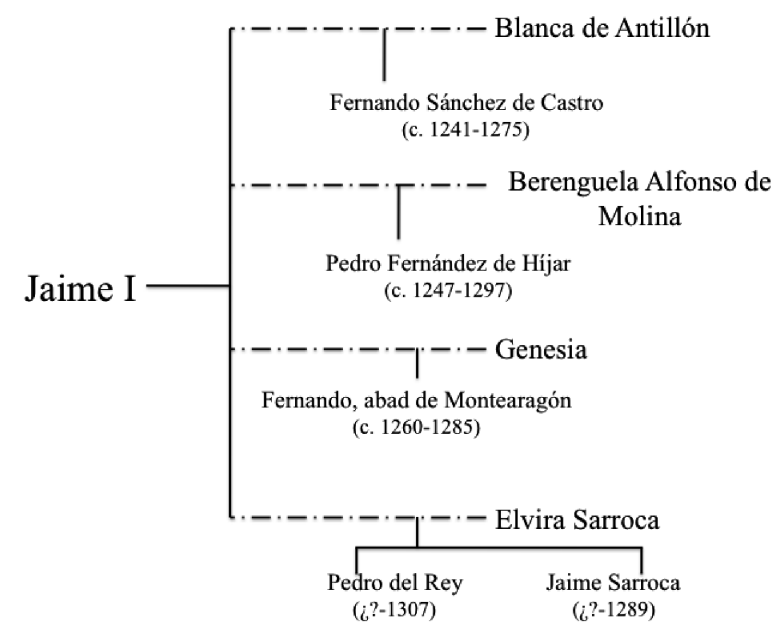

Descendencia de Federico II:

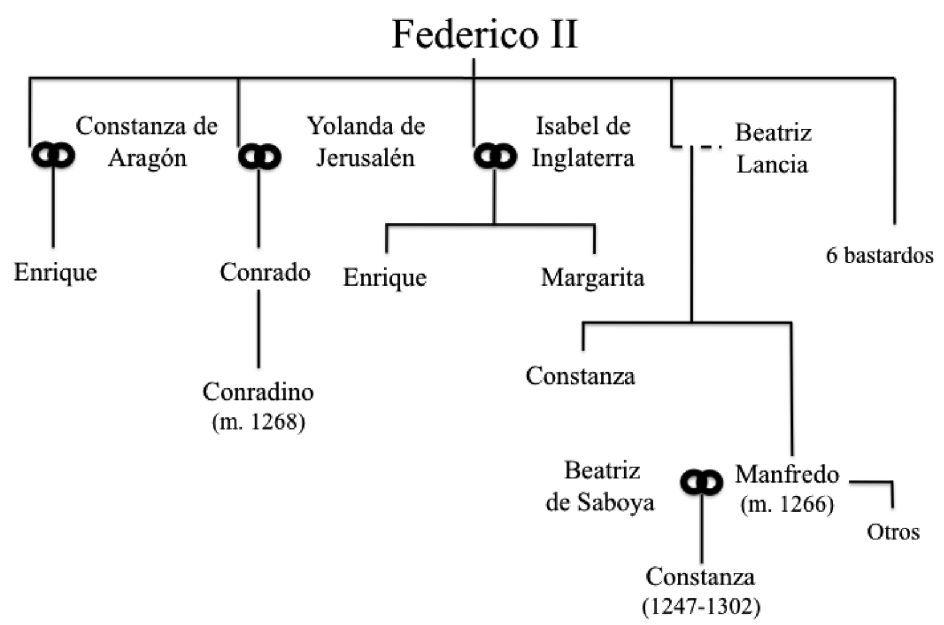

64.- Se sigue aquí lo mencionado por S. M. Cingolani, "Fernando, abad de Montearagón”, pp. 44 y ss. Sin embargo, tengo mis reservas en aceptar que los Sarroca fueran hijos del rey, ya que éste en múltiples ocasiones habla de Jaime Sarroca, quien será obispo de Lérida como alguien de su entorno áulico. Sin embargo, jamás dice que sea hijo suyo, cosa que sí hace con otros de sus ilegítimos. Un ejemplo documental se encuentra en ACA, Cancillería, Reg. 15, fol. 40v, apud A. Huici Miranda y M ${ }^{\mathrm{a}} \mathrm{D}$. Cabanes Pecourt, Documentos de Jaime I, vol. V, p. 207: "Per nos et nostros recognoscimus et confitemur quod vos Jacobus de Rocha, sacriste ilerdensis, decanus Valencie et notarius noster [...]". 
